\title{
Active travel is (generally) good for health, the environment and the economy
}

\section{Dr Jennifer S Mindell}

There are at least 580 million bicycles globally; $42 \%$ of private households own at least one bicycle (Oke et al, 2015). Even more people could be pedestrians, so the many articles in this issue related to active travel are almost universal in relevance. This issue explores different facets of active travel, including quantifying current activity patterns; exploring inequalities; measuring and modelling the impact of interventions aimed at promoting active travel; and looking at the health, environment and economic impacts.

Interventions to change commuting behaviour through workplace travel policies are often proposed but seldom evaluated rigorously (Macmillan et al, 2013). Petrunoff and colleagues (2015) report on a natural experiment (see Craig et al, 2010) in which two nearby hospitals had different interventions to encourage active travel and discourage walking. They found that driving by employees reduced more at the hospital that used disincentives to driving as well as incentives to active travel. The application of disincentives is also important at national levels. Pucher and Buehler (2008) found that the rise in cycling in Denmark, Germany and the Netherlands followed not only the oftacclaimed investment in cycling infrastructure but also financial and other disincentives to car ownership, parking, and use. Brown et al (2015) also used natural experiments to examine the impacts of congestion charging on physical activity. Their main conclusion relates to the inadequacy of current evidence. Adams and Cavill (2015) also make recommendations for future evaluation of environmental improvements to pedestrian routes.

A modelling study in a hypothetical Dutch city suggests that building on-road cycle lanes and separated cycle paths is likely to reduce all-cause mortality, primarily through increasing physical activity plus small contributions from reduced air pollution exposure and reduced injuries (Schepers et al, 2015). Similarly, a second modelling study, of new cycle highways in Flanders, also predicts reduced mortality and morbidity from increased physical activity, despite small increases in new cyclists' air pollution exposure and injuries (Buekers et al, 2015). The latter study also calculated that the economic benefits to society outweighed the costs under most assumptions. The particular conditions of a specific city will, however, affect these conclusions (Tainio, 2015).

Measurement is a recurring theme, including examining exposures of pedestrians to air pollution (do Vale et al, 2015) and children's independent mobility (Bhosale et al, 2015). Commuting to school among adolescents in southwest England tracked through adolescence, with around a third commuting actively at each wave of the longitudinal study. Active travel was associated with a lower body mass index (BMI) in males but not in females (Falconer et al, 2015). Boys in Toronto, Canada were more likely than girls to walk to school; parental perceptions of traffic safety in the context of neighbourhood environment was associated more with boys' than girls' commuting mode (Guliani et al, 2015).

This issue also contains an article on social exclusion (Mackett and Thoreau, 2015) which takes as its starting point a chapter in Health on the Move 2 (Mindell, 2014). It is accompanied by a commentary giving a non-UK perspective (Corburn, 2015). Improvements in the walking environment are 
particularly important to the more deprived sectors of the population who have few transport options. Burden and Litman (2011) examine the benefits of creating Complete Streets that facilitate active travel. An ecological study by Braun and Malizia (2015) across 48 large cities in the USA found that the greater the vibrancy of the downtown area, the lower the prevalence of physical inactivity and of motor vehicle fatalities at county level. Karner and colleagues (2015) report that socially disadvantaged groups are disproportionately exposed to transport-related heat. In 2012, although around half of primary schools in England had offered free, high quality cycle training to children this reduced but did not eliminate social inequalities in participation in cycle training (Goodman et al, 2015). Meanwhile, powered two-wheelers, disproportionately used by people in Asia with lower income and education levels, are used almost three times as much by the indigenous population in Taiwan, accounting for much of their excess risk of road fatalities (Pan et al, 2015). Although 98\% of women in 6 US metropolitan areas had access to a car or were within 30 minutes of mammography facilities by public transport (transit), lower middle income and minority groups were most transit marginalised, particularly in cities with less public transport (Graham et al, 2015).

Ciclovias (Mindell, 2015), referred to as Open Streets initiatives in the USA, aim to promote cycling as physical activity. Chaudhuri and Zieff (2015, Editor's Choice) have demonstrated that they also have beneficial economic effects on local businesses. This supports a growing body of evidence showing that pedestrianisation or removal of all, or private, motor vehicles generally increases footfall for local businesses, as highlighted in the review by Transport for London (2002) which found "overwhelming economic benefit" of city centre pedestrian and urban realm improvement schemes.

A number of organisations have published reviews of a wide range of effects of improving the pedestrian environment (Tolley, 2011; Lawlor, 2015). Pedestrianisation can increase retail footfall by $20-40 \%$ and retail turnover by $10-25 \%$ (Whitehead et al, 2006). Non-motorised transport projects, including walking, increase retail sales by around 30\% (Burden \& Litman, 2011). Pedestrians and cyclists spent more per month than those arriving by motorised transport in both Toronto, Canada and Auckland, New Zealand (Tolley, 2011; Wooller, 2010). In Auckland, shoppers spent similar amounts per visit regardless of travel mode but those travelling by foot or bicycle visited more frequently (Wooller, 2010). Although car drivers spent more per trip in London town centres in 2011, pedestrians and bus passengers made more trips and spent more overall: pedestrians spent $£ 147$ more per month than car drivers and passengers (Tyler et al, 2012). Despite initial opposition to proposed schemes (Kumar \& Ross, 2006), many businesses find financial benefits after implementation; there are increasing numbers of cases where local businesses support extension of the scheme (Kumar \& Ross, 2006). However, as Adams and Cavill (2015) warn, there is evidence that increasing pedestrian use of improved local routes may take time.

There is work to be done to realise the benefits of active travel, and investment is needed both to change infra-structure and to support behaviour change - this issue provides evidence in both these areas.

\section{Acknowledgements}

I thank the handling editor for helpful suggestions on the draft editorial.

\section{References}


Adams E, Cavill N (2015). Engaging communities in changing the environment to promote transportrelated walking: evaluation of route use in the 'Fitter for Walking' project. Journal of Transport and Health. 2(4): in this issue

Bhosale J, Duncan S, Schofield G, Page A, Cooper A (2015). A pilot study exploring the measurement of intergenerational differences in independent mobility. Journal of Transport and Health. 2(4): in this issue

Braun LM, Malizia E (2015). Downtown vibrancy influences public health and safety outcomes in urban counties. Journal of Transport and Health. 2(4): in this issue

Brown V, Moodie M, Carter R (2015). Congestion pricing and active transport - evidence from five opportunities for natural experiment. Journal of Transport and Health. 2(4): in this issue

Buekers J, Dons E, Elen B, Int Panis L (2015). Health impact model for modal shift from car use to cycling or walking in Flanders: application to two bicycle highways. Journal of Transport and Health. 2(4): in this issue

Burden D, Litman T (2011). America Needs Complete Streets. ITE Journal. 81(4):36-43.

Chaudhuri A, Zieff SG.(2105) Do Open Streets initiatives impact local businesses? The case of Sunday Streets in San Francisco, California. Journal of Transport and Health. 2(4): in this issue

Corburn J (2015). Inclusive and health cities: Commentary on Transport, social exclusion and health. Journal of Transport and Health. 2(4): in this issue

Craig P, Cooper C, Gunnell D, Haw S, Lawson K, Macintyre S, Ogilvie D, Petticrew M, Reeves B, Sutton $\mathrm{M}$, Thompson S (2010). Using natural experiments to evaluate population health interventions: guidance for producers and users of evidence. Medical Research Council. London: Medical Research Council. www.mrc.ac.uk/documents/pdf/natural-experiments-guidance/ (accessed 24/07/2015)

Guliani A, Mitra R, Buliung R, Larsen K, Faulkner G. (2015) Gender-based differences in school travel mode choice behaviour: Examining the relationship between the neighbourhood environment and perceived traffic safety. Journal of Transport and Health. 2(4): in this issue

Goodman A, van Sluijs E, Ogilvie D (2015). Cycle training for children: which schools offer it and who takes part? Journal of Transport and Health. 2(4): in this issue

Graham S, Lewis B, Flanagan B, Watson M, Peipins L (2015). Travel by public transit to mammography facilities in 6 US urban areas. Journal of Transport and Health. 2(4): in this issue

Karner A, Hondula DM, Vanos JK (2015). Heat exposure during non-motorized travel: Implications for transportation policy under climate change. Journal of Transport and Health. 2(4): in this issue

Kumar S, Ross W (2006). Effects of Pedestrianisation on the Commercial and Retail Areas: Study in Khao San Road, Bangkok. World Transport Policy \& Practice. 13(1):38-50.

Lawlor E (2015). The pedestrian pound: The business case for better streets and places. London: Living Streets.

Mackett R, Thoreau R. Transport, social exclusion and health. (2015) Journal of Transport and Health. 2(4): in this issue 
Macmillan, A. K., Hosking, J., Connor, J. L. , Bullen C., Ameratunga S (2013). A Cochrane systematic review of the effectiveness of organisational travel plans: Improving the evidence base for transport decisions. Transport Policy 29:249-256.

Mindell JS (2014). Health on the Move 2. Policies for health-promoting transport. Journal of Transport and Health. 1(1): 2.

Mindell JS (2015). The impacts of national and local government actions on active travel. Journal of Transport and Health. 2(2): 95-96.

Oke O, Bhalla K, Love DC, Siddiqui S (2015). Tracking global bicycle ownership patterns. Journal of Transport and Health. 2(4): in this issue

Pan SW, Hsu C-T, Brussoni M, Pike I. (2015) Indigenous ethnicity as a social determinant of exposure to riskier modes of transport: a survey study in Taiwan. Journal of Transport and Health. 2(4): in this issue

Petrunoff N, Rissel C, Wen LM. (2015) Carrots and sticks vs carrots: Comparing approaches to workplace travel plans using disincentives for driving and incentives for active travel. Journal of Transport and Health. 2015;2(4): in this issue.

Pucher J, Buehler R (2008). Making Cycling Irresistible: Lessons from The Netherlands, Denmark and Germany. Transport Reviews. 28(4): DOI:10.1080/01441640701806612

Schepers P, Fishman E, Beelen R, Heinen E, Wijnen W, Parkin J (2015). The mortality impact of bicycle paths and lanes related to physical activity, air pollution exposure and road safety. Journal of Transport and Health. 2(4): in this issue

Tainio M (2015). Burden of disease caused by local transport in Warsaw, Poland. Journal of Transport and Health. 2(3):423-33.

Tolley R (2011). Good for Busine\$s: The Benefits of Making Streets More Walking and Cycling Friendly. Discussion Paper. Adelaide: National Heart Foundation of Australia.

Transport for London (2002). The benefits of town centre pedestrian and public realm schemes. London: Transport for London.

Tyler S, Semper G, Guest P, Fieldhouse B (2012). The relevance of parking in the success of urban centres. A review for London Councils. London: The Means.

do Vale ID, Vasconcelos AS, Duarte GO (2015). Inhalation of particulate matter in different routes for the same OD pair: a case study with pedestrians in Lisbon. Journal of Transport and Health. 2(4): in this issue

Whitehead T, Simmonds D, Preston J (2006) The Effect of Urban Quality Improvements on Economic Activity. Journal of Environmental Management. 80 (1): 1-12.

Wooller LA (2010). What are the economic and travel implications of pedestrianising a roadway in Takapuna's shopping precinct. Thesis for Master of Health Science degree. Auckland: University of Auckland. http://aut.researchgateway.ac.nz/handle/10292/999 